\title{
Corrida de Toras: Jogo didático para um ensino intercultural
}

\author{
Elisa Augusta Lopes Costa ${ }^{1}$ \\ Francisco Edviges Albuquerque ${ }^{2}$ \\ Programa de Pós-graduação em Letras: Ensino de Língua e Literatura, \\ Universidade Federal do Tocantins, Araguaína, Tocantins, Brasil
}

Resumo: Este artigo aborda a possibilidade de criação de jogos didáticos para a Educação Escolar Indígena Krahô, mais especificamente na Escola Indígena 19 de Abril, localizada na aldeia Manoel Alves Pequeno, ao nordeste do estado do Tocantins. Tem como objetivo demonstrar que a ludicidade pode ser um elemento valioso na educação intercultural. A metodologia, de perspectiva sociointeracionista, compõe-se de oficinas de confecção e manipulação de materiais alternativos que incluem jogos didáticos como elemento potencializador da aprendizagem da língua portuguesa como segunda língua. $O$ jogo Corrida de Toras, que mescla elementos da cultura não indígena e da cultura Krahô, foi desenvolvido no decorrer das oficinas e passou a ser utilizado pelos professores indígenas em sua prática docente como estratégia para revisão de conteúdos.

Palavras-chave: Educação lúdica; Educação escolar indígena; Jogos didáticos; Interculturalidade.

Title: Corrida de Toras: Didactic game for an intercultural education

Abstract: This article discusses the possibility of creation of didactic games for the Krahô Indigenous Schooling Education, more specifically at the 19 de Abril Indigenous School, located in Manoel Alves Pequeno village, in the northeast of the state of Tocantins. It aims to demonstrate that playfulness can be a valuable element in intercultural education. The methodology, from a socio-interactionist perspective, is made up of workshops for the preparation and manipulation of alternative materials that include didactic games as a potentiating element in the learning of the Portuguese language as a second language. The game Corrida de Toras, which combines elements of non-indigenous culture and Krahô culture, was developed during the workshops and started to be used by indigenous teachers in their teaching practice as a strategy for reviewing content.

Keywords: Playful education; Indigenous schooling education; Didactic games; Interculturality.

\footnotetext{
${ }^{1}$ Doutoranda do Programa de Pós-graduação em Letras: Ensino de Língua e Literatura, UFT/Araguaína Professora de Prática de Ensino da Faculdade de Letras/UFPA/Altamira. Orcid: http://orcid.org/00000002-4859-8764

E-mail: elisakosloski@gmail.com

${ }^{2}$ Orientador da pesquisa. Professor Associado II da Universidade Federal do Tocantins/Araguaína.

Orcid: http://orcid.org/0000-0002.0004-1887

E-mail: fedviges@uol.com.br
} 


\section{Introdução}

Uma das principais características das escolas indígenas no Brasil é a necessidade de lidar com, no mínimo, duas línguas e duas culturas diferentes. Esta situação requer um ensino essencialmente intercultural, dadas as relações entre as culturas dos indígenas e da sociedade envolvente, tornando a escola indígena um lugar de negociação entre identidades e interesses diferentes, que precisam chegar a um consenso, sem desmerecer nenhuma das culturas envolvidas.

Esta condição está presente na realidade das escolas existentes na terra indígena do povo Krahô, alvo desta pesquisa, a qual se concretizou na Escola Indígena 19 de Abril, localizada na Aldeia Manoel Alves Pequeno, contando com a participação de todos os professores da escola, sendo 8 indígenas e dois não indígenas. Estes professores ministram aulas para o Ensino Fundamental, Ensino Médio e Educação de Jovens e Adultos - EJA. A pesquisa, realizada entre 2015 e 2016, consistiu na apresentação de uma proposta de ensino baseada na educação lúdica como uma alternativa para estabelecer, de forma prazerosa, um diálogo entre diferentes visões de mundo, facilitando a negociação de soluções para os conflitos que podem surgir na relação intercultural.

A metodologia, de perspectiva sociointeracionista, compõe-se de oficinas de confecção e manipulação de materiais alternativos que incluem jogos didáticos como elemento potencializador da aprendizagem da língua portuguesa como segunda língua ${ }^{3}$. Este artigo concentra-se na apresentação do jogo Corrida de Toras, que foi desenvolvido no decorrer das oficinas e mescla elementos da cultura não indígena e da cultura Krahô, o que o torna uma demonstração de boas relações interculturais.

O texto está desenvolvido a partir da apresentação dos aspectos históricos do povo Krahô, abordando também a educação tradicional e a presença da ludicidade na cultura deste povo. ensino intercultural. A seguir, são tecidas considerações sobre ensino intercultural, educação lúdica e o desenvolvimento dos jogos didáticos sugeridos para o ensino intercultural na Escola 19 de Abril, finalizando com a exposição sobre o jogo Corrida de Toras.

\section{O povo Krahô: aspectos históricos}

O povo Krahô é identificado como pertencente ao grupo Timbira, da família linguística Jê, por compartilhar com estes povos características linguísticas e culturais. O nome Krahô, segundo Albuquerque (2013), significa "pelo de paca": Hô = pelo e cra = paca, conforme explicação que estes indígenas teriam dado a Curt Nimuendajú em 1930. Entretanto, ainda de

\footnotetext{
${ }^{3}$ Cf. Projeto de pesquisa intitulado Ludicidade com recursos visuais: uma proposta para a educação escolar indígena Krahô, CAAE 59502916.6.0000.5519.
} 
acordo com Albuquerque, trinta anos depois, indígenas da mesma etnia discordavam desta versão, alegando ser o nome Krahô uma invenção dos civilizados.

A história deste povo começa a ser conhecida a partir do momento em que se efetiva o contato com a sociedade não-indígena. De acordo com Melatti (2009), os primeiros registros da existência do povo Krahô datam do início do século XIX, quando estes índios habitavam uma área no sul do Maranhão, delimitada pelos rios Tocantins, Farinha, Itapecuru, Parnaíba, Perdida e Sono. Segundo Ribeiro (1841) e Nimuendajú (1946), eles eram conhecidos inicialmente por Macamekrans.

De acordo com Melatti, o contato se deu em virtude da convergência de duas frentes colonizadoras (agrícola e pastoril), que avançavam do litoral para o interior do país. Devido aos numerosos conflitos entre índios e colonizadores, o povo Krahô foi paulatinamente sendo expulso de seu antigo território, sendo forçado a avançar em direção ao rio Tocantins. Entretanto, os indígenas não se davam por vencidos e atacavam as fazendas de gado que vinham sendo formadas pelos invasores. Por outro lado, os fazendeiros reagiam em represália, aumentando as hostilidades entre ambos os lados.

Na tentativa de minimizar os conflitos, em 1848 os Krahô foram transferidos para um aldeamento localizado em Pedro Afonso (TO) e estabelecido por Frei Rafael de Taggia (missionário capuchinho vindo da Itália). Com isso, satisfazia-se, ao mesmo tempo, o desejo de trazer os índios para a religião católica e os interesses dos fazendeiros, que queriam vê-los distantes da zona pastoril. Entretanto, segundo informa Melatti, os Krahô não ficaram muito tempo em Pedro Afonso, mas foram se deslocando para o norte, até ocupar o território onde vivem atualmente, localizado em Goiatins e Itacajá, ao nordeste do estado do Tocantins. Essa área, que passou a ser denominada Kraholândia, foi demarcada pelo decreto presidencial no 102, (BRASIL, 1944), mas só foi homologada pelo Decreto-Lei no 99.062 (BRASIL, 1990).

Naquele local havia, em 1930, três aldeias, conforme informação de Curt Nimuendaju (1946, p. 26). Em 1967, segundo Melatti (2012), já havia ali cinco aldeias. Atualmente, de acordo com Macedo (2015), são vinte e nove aldeias. Melatti informa que a população Krahô contava entre três a quatro mil pessoas em 1809, tendo sido reduzida a 620 indivíduos na metade do século XIX, chegando a existirem apenas 519 indígenas vivendo na Kraholândia em 1963 (Melatti, 2012, p. 22). A partir daí houve um aumento da população. Segundo Araújo (2015), em 2010, o número de indígenas passava de 2400, chegando a 3264 em 2015.

A partir destes dados verifica-se que este povo, assim como outros povos indígenas do Brasil, depois de quase ter sido destruído, apresenta franca recuperação populacional. Além disso, também é notória a preocupação com a preservação de sua cultura. Entre os costumes culturais preservados pelos Krahô destacam-se a construção das aldeias em formato circular e a Corrida de Toras. As casas dos Krahô são construídas ao redor de um grande círculo formado por uma rua de terra batida, que Nimuendajú chama de rua circular (1944, p. 76). No centro da aldeia fica o pátio, ligado à rua circular por caminhos radiais, também de terra batida. 
As corridas de toras são realizadas sempre em associação com algum rito, segundo o qual variam os grupos participantes, a forma das toras e o percurso da corrida. Conforme a descrição de Melatti (1976), utilizam-se sempre duas toras iguais, havendo ocasiões rituais que requerem mais de duas para cada grupo participante, que são sempre os membros de metades opostas. As toras são feitas, na maioria das vezes, do tronco do buriti. Entretanto, há uma variedade de formatos de tora, feitas com materiais e tamanhos diferentes. A corrida se inicia geralmente fora da aldeia, podendo o ponto de partida variar de algumas centenas de metros até alguns quilômetros de distância da aldeia, dependendo do rito que esteja sendo realizado. Ao entrar na aldeia, a corrida prossegue no caminho circular, sempre na direção anti-horária. O ponto de encerramento da corrida é o pátio ou uma das casas de wỳhtỳ4. Podem ser feitas também corridas apenas dentro da aldeia, mas nunca se faz uma corrida de dentro para fora dela.

A corrida se inicia quando um dos membros do grupo, ajudado pelos companheiros, coloca a tora aos ombros e sai correndo, seguido pelos demais. Assim que este se mostra cansado, um dos companheiros o substitui. Desta forma, a tora vai sendo passada de um ombro a outro até o final da corrida. As corridas ocorrem diariamente, podendo acontecer pela manhã e à tarde.

As mulheres e as crianças também participam de corridas de toras, semelhantemente à corrida masculina, embora este fato ocorra bem mais raramente. No caso da corrida de crianças, o diferencial é que correm meninos contra meninas. As toras destinadas às corridas de mulheres são mais leves que as dos homens, assim como também para as corridas infantis são confeccionadas toras compatíveis com a capacidade física das crianças.

O fato de homens e mulheres participarem de corridas distintas está relacionado à forma de organização social dos Krahô, que se caracteriza por diversos grupos binários, chamados de metades, destacando-se o par de metades que representa o inverno e o verão, respectivamente Wakmẽjê e Katamjê. Os índios Krahô costumam ornamentar-se com pinturas corporais, as quais são feitas de acordo com as características destas metades principais, sendo que os indivíduos pertencentes ao grupo Wakmẽjê usam pinturas horizontais, enquanto os pertencentes ao grupo Katamjê usam pinturas verticais.

\section{Educação tradicional Krahô e Ludicidade}

Apesar de um intenso contato com agentes externos, o povo Krahô vem conseguindo manter sua identidade cultural fortalecida, o que se deve à ênfase na preservação de seus princípios próprios de educação, conforme constata Abreu (2012). Segundo esta autora, os

\footnotetext{
${ }^{4}$ As casas wỳhtỳ são um local de acolhimento. Qualquer visitante, indígena ou não, tem livre entrada nessa casa, onde recebe alimento. Segundo Araújo (2015, p. 161), não há uma tradução literal para o termo, mas os próprios indígenas a identificam com uma pensão ou hotel, assimilando suas características com as destes estabelecimentos da cultura não indígena.
} 
Krahô mantém uma política interna de fortalecimento da sua língua e cultura, de modo que insistem que os saberes tradicionais sejam transmitidos às crianças somente em língua materna.

Nesta perspectiva, as crianças aprendem por meio de observação e imitação, a partir da convivência diária com os adultos, na interação com outras crianças da aldeia, e também durante os eventos no pátio central, onde são realizadas muitas das atividades importantes para a cultura Krahô, como a divisão do trabalho, a prática dos rituais e a tomada de decisões. Além de tudo isso, há também momentos específicos de ensino e aprendizado, os quais são conduzidos por alguém designado para este fim.

Na educação tradicional Krahô, existe a figura do Mē hahkrecatê ou Ihkrãri catê (instrutor ou professor na língua Krahô), responsável pelo ensino dos saberes indígenas para as crianças. Os alunos acompanham o seu instrutor pela aldeia e pela mata, aprendendo conteúdos básicos sobre seu território, sua cultura e para sua sobrevivência. O processo educacional acontece de forma peculiar, o ensino é livre de qualquer determinação burocrática e a aprendizagem é coletiva e colaborativa. (LEITE, 2017, p. 50).

Percebe-se que a ludicidade está presente neste modelo de educação, que se caracteriza pela aprendizagem em movimento, permeada pela liberdade e espontaneidade. As crianças Krahô são preparadas para a vida adulta, aprendendo na prática, auxiliando os adultos em suas atividades, entretanto, conforme indica Melatti (2012), não se exige das crianças trabalhos cansativos, indicando-lhes tarefas que se aproximam de divertimentos, como, por exemplo, ajudar os mais velhos a espantar periquitos na roça, no tempo do amadurecimento do arroz.

Deste modo, a transmissão de conhecimentos da cultura Krahô ocorre de forma espontânea, tranquila e lúdica, em consonância com a colocação de Melià (1979), o qual lembra que a criança indígena, como qualquer outra, aprende brincando, sendo diferente apenas no fato de que o brinquedo geralmente consiste em exemplares menores dos instrumentos de trabalho do pai ou da mãe. As brincadeiras das crianças Krahô estão geralmente interligadas à vida social, refletindo situações do cotidiano.

As meninas brincam com cuia. Colocam arroz, batata, grolado e brincam muito debaixo das árvores na aldeia. Levam seus cofinhos e colocam massa de mandioca e outras comidas para brincarem em outros lugares com as amigas. Lá amarram seus panos em galhos e fazem uma casinha, pegam pedras, fazem o fogão, acendem o fogo e ali fazem suas comidas como veem fazer em suas casas, elas gostam muito de fazer esse tipo de brincadeira. Os meninos levam badoque, arco e flecha para matarem passarinhos e levam para as meninas para fazerem moquém. Os meninos cortam buriti para correrem juntos com as meninas até chegarem à aldeia. Depois descansam um pouco e todos vão tomar banho no rio. Os meninos também gostam de brincar de jogar flechas para ver quem joga mais longe. Gostam de brincar de correr no pátio durante 
a noite, as crianças brincam muito, gostam de subir nas árvores e ficar balançando. (CY KRAHÔ, in ALBUQUERQUE, 2014, p. 46).

A ludicidade também está presente na cultura Krahô na forma de jogos e brincadeiras que ocorrem não apenas entre as crianças, mas também com a participação dos adultos. Há uma série de jogos que retratam situações vivenciadas pela comunidade, seja em relação às plantações (brincadeira da melancia ou macaco roubando milho), como referindo-se a situações de caça, sobrevivência no cerrado ou defesa de território (brincadeira do tamanduábandeira, gavião e galinha, brincadeira de luta). De acordo com Meliá, nas culturas indígenas, os jogos apresentam uma dimensão educativa, à medida que se constituem como espaços privilegiados de aprendizagens sociais, de resistência e afirmação de identidades. Tendo em vista o potencial educativo dos jogos, os professores Krahô incluem a ludicidade na educação escolar, por meio de brincadeiras tanto nas aulas como nos períodos de recreação, tendo o cuidado de mostrar aos alunos quais são as brincadeiras da cultura indígena e quais as oriundas da sociedade envolvente.

\section{Educação bilíngue e intercultural}

A Escola Indígena 19 de Abril, localizada na aldeia Krahô Manoel Alves Pequeno, destaca-se pelo esforço para levar a efeito uma educação bilíngue e intercultural, pautada pela legislação brasileira que the garante este direito, destacando-se, entre outros documentos: o Estatuto do Índio (BRASIL, 1973, Lei 6001, art. 49); a Constituição Federal do Brasil (BRASIL, 1988, Arts. 210, 215, 231); Lei de Diretrizes e Bases da Educação Nacional LDBEN 9394, (BRASIL, 1996, arts. 78 e 79); Referencial Curricular Nacional para as Escolas Indígenas - RCNEI (BRASIL, 1998); Plano Nacional de Educação - PNE 10.172/2001 (BRASIL, 2001).

Estes são os principais documentos que garantem aos povos indígenas o direito à preservação de suas organizações sociais, línguas, crenças e costumes próprios, possibilitando, por meio da instituição escolar, a recuperação de suas memórias históricas, a reafirmação de suas identidades étnicas e a valorização de suas línguas e ciências, além de Ihes garantir o acesso às informações, conhecimentos técnicos e científicos da sociedade nacional e demais sociedades indígenas e não-indígenas.

Com base nesta legislação, que prevê novas organizações curriculares baseadas nas noções de pluralismo cultural e de diversidade étnica, preconizando que a Educação Escolar Indígena deve ser comunitária, intercultural, bilíngue/multilíngue, específica e diferenciada, a Escola 19 de Abril empenhou-se na construção de um Projeto Político Pedagógico próprio, voltado para os anseios da comunidade local.

Nesta perspectiva, e apoiado na Proposta Pedagógica da Educação Escolar Indígena do Estado do Tocantins - PPEEI/TO (TOCANTINS, 2013), foi elaborado um projeto que se 
desenvolve em dois eixos, distribuindo o tempo escolar em tema e disciplina, abordados em semanas alternadas. Em uma semana trabalham-se as disciplinas relacionadas aos saberes escolares. Na semana seguinte, abordam-se os saberes indígenas.

A equipe dos professores da Escola 19 de abril é formada, em sua maioria, por professores indígenas que dominam tanto a língua materna quanto a língua portuguesa, o que auxilia na transposição dos aspectos orais para a escrita da língua Krahô, e também confere mais eficiência na alfabetização em ambas as línguas, bem como na ministração de outras disciplinas, pois o intercâmbio entre as línguas ajuda quando há necessidade de esclarecimento acerca de conceitos, particularmente da educação escolar.

O conceito de educação bilíngue e intercultural para as escolas indígenas começa a ser delineado na legislação brasileira a partir da Constituição de 1988, mas assume contornos mais nítidos com a legislação subsequente, acima mencionada. Tais leis destacam positivamente as especificidades culturais dos povos indígenas e ressaltam a existência dos seus processos tradicionais de transmissão do conhecimento.

(...) as sociedades indígenas são portadoras de tradições culturais específicas e vivenciaram processos históricos distintos. Cada um desses povos é único, tem uma identidade própria, fundada na própria língua, no território habitado e explorado, nas crenças, costumes, história, organização social. Por outro lado, as sociedades indígenas compartilham um conjunto de elementos básicos que são comuns a todas elas e que as diferenciam da sociedade não-indígena. Assim, os povos indígenas têm formas próprias de ocupação de suas terras e de exploração dos recursos que nelas se encontram; têm formas próprias de vida comunitária; têm formas próprias de ensino e aprendizagem, baseadas na transmissão oral do saber coletivo e dos saberes de cada indivíduo. (BRASIL, 1994, p. 10).

Este documento define interculturalidade como "o intercâmbio positivo e mutuamente enriquecedor entre as culturas das diversas sociedades" afirmando a necessidade de que esta seja uma característica básica das escolas indígenas (idem, p. 11). A interculturalidade ocorre por meio de um diálogo constante entre as culturas envolvidas, tendo em conta que o intercâmbio e as contribuições entre línguas são processos que ocorrem em todas as sociedades ao longo de sua história.

De acordo com Guimarães (2006), a interculturalidade leva em conta a diversidade cultural no processo de ensino e aprendizagem. Em outras palavras, a escola deve dar tratamento didático aos valores, saberes e conhecimentos tradicionais bem como às práticas sociais de cada cultura, sem deixar de garantir o acesso aos conhecimentos e tecnologias que sejam relevantes para o processo de interação e participação cidadã na sociedade nacional.

Com isso, as atividades curriculares devem ser significativas e contextualizadas às experiências dos educandos e educandas e de suas comunidades. A nova escola indígena propõe ser espaço intercultural, onde se debatem e se constroem conhecimentos e estratégias sociais sobre a situação de contato interétnico. Podem ser conceituadas como escolas de fronteira, ou seja, 
espaços públicos em que situações de ensino e aprendizagem estão relacionadas às políticas identitárias e culturais de cada povo indígena. (GUIMARÃES, 2006, p. 20).

Nesta perspectiva, o Referencial Curricular Nacional para as Escolas Indígenas (RCNEI) considera que a Educação Escolar Indígena, para ser intercultural, deve

\begin{abstract}
reconhecer e manter a diversidade cultural e linguística; promover uma situação de comunicação entre experiências socioculturais, linguísticas e históricas diferentes, não considerando uma cultura superior à outra; estimular o entendimento e o respeito entre seres humanos de identidades étnicas diferentes, ainda que se reconheça que tais relações vêm ocorrendo historicamente em contextos de desigualdade social e política. (BRASIL, 1998, p. 24).
\end{abstract}

Cada povo indígena vive uma situação sui generis em sua relação com a sociedade envolvente, particularmente no que se refere à situação linguística, havendo diferenciados graus de bilinguismo e também de multilinguismo. É isso que caracteriza a escola indígena como específica e diferenciada, porque há a necessidade de se adaptar conteúdos e currículos à realidade de cada povo e sua escola, a partir do "diálogo, do envolvimento e do compromisso dos respectivos grupos indígenas, como agentes e co-autores de todo o processo" (BRASIL, 1994, p. 11). As escolas indígenas não diferem somente das escolas urbanas, mas também umas das outras, uma vez que se trata de línguas e culturas diferentes, que serão os elementos constituintes de cada escola.

De acordo com Maher (2007), para as populações indígenas do Brasil, o bilinguismo é uma condição compulsória, pois, devido às necessidades de convivência com a sociedade nacional, é imperativo aprender o português. Em relação à educação escolar bilíngue, Maher (2006) afirma que esta se insere em dois paradigmas distintos: o assimilacionista e o emancipatório. O primeiro, instaurado com o ensino jesuítico, empenha-se em

educar o índio para que ele deixe de ser índio: o objetivo do trabalho pedagógico é fazê-lo abdicar de sua língua, de suas crenças e de seus padrões culturais e incorporar, assimilar os valores e comportamentos, inclusive linguísticos, da sociedade nacional. (MAHER, 2006, p. 20).

Sob os princípios do segundo paradigma, o Emancipatório, surge o Modelo de Enriquecimento Cultural e Linguístico, que procura promover um bilinguismo aditivo. Conforme Maher,

pretende-se que o aluno indígena adicione a língua portuguesa ao seu repertório linguístico, mas pretende-se também que ele se torne cada vez mais proficiente na língua de seus ancestrais. Para tanto, insiste-se na importância de que a língua de instrução seja a língua indígena ao longo de todo o processo de escolarização e não apenas nas séries iniciais. Além disso, esse modelo 
busca promover o respeito às crenças, aos saberes e às práticas culturais indígenas. (MAHER, 2006, p. 22).

Convém destacar que a implantação deste novo paradigma ocorreu em decorrência do movimento político das associações indígenas que começaram a se mobilizar no final da década de 1970 e dos consequentes avanços na legislação nacional voltada para os povos indígenas, iniciados com a Constituição Federal de 1988. De acordo com Mori (2001), a educação bilíngue e intercultural se constitui, para os povos indígenas, em uma estratégia política de manutenção da sua língua e cultura, além do esforço por uma participação ativa na vida econômica, social, política e cultural da sociedade nacional. Segundo o autor,

A educação bilíngue não deve ser apenas uma ponte para chegar à sociedade nacional. A educação bilíngue deve considerar as culturas dos povos indígenas para, posteriormente, gerar um diálogo crítico e criativo com outras culturas. Nesse aspecto, uma educação bilíngue bem entendida deve estar orientada para uma interculturalização regional, nacional e internacional. (MORI, 2001, p. 167).

Mori acrescenta que a educação bilíngue e intercultural deve possibilitar o bilinguismo individual e social, estabelecendo redes e instâncias de intercâmbio cultural e linguístico. Para alcançar este objetivo, há três aspectos relevantes: a formação de professores indígenas, a elaboração de materiais didáticos e o desenvolvimento de um currículo diversificado que leve em conta a realidade sociocultural de cada povo indígena e que também contenha matérias relacionadas com a problemática regional, nacional e internacional. Esta colocação está em consonância com o artigo 79 da LDB 9.394 (BRASIL, 1996), que destaca a responsabilidade do governo federal, em conjunto com os demais sistemas de ensino, no desenvolvimento de programas integrados de ensino e pesquisa.

Diante de todas estas considerações, verifica-se que a educação bilíngue e intercultural se refere a uma prática de educação escolar que lida com os dois universos que fazem parte da existência indígena, possibilitando tanto o domínio dos códigos e conhecimentos utilizados pela sociedade nacional quanto a valorização e divulgação da língua, cultura e identidade indígenas.

\section{Educação lúdica e interculturalidade na Escola 19 de Abril}

A expressão educação lúdica vem sendo utilizada para definir uma metodologia que busca alcançar melhores resultados por meio de estratégias de ensino que estimulem o aluno à curiosidade, à descoberta, ao desejo de aprender. A educação lúdica está alicerçada em autores de épocas diversas, desde os filósofos gregos até os pensadores atuais. Platão (2000) preconizava que a educação das crianças deveria começar pelas fábulas, e que os 
ensinamentos deveriam ser transmitidos a partir dos jogos por serem estes inerentes à natureza das crianças.

O termo ludicidade tem origem na palavra latina ludus, que significa jogo, divertimento, passatempo, jogos públicos, representações teatrais, escola, aula. Convém lembrar que a palavra escola também tem, no latim, um sentido de diversão ou recreação. Schola, o termo latino, origina-se do grego skholê, que, além de significar escola ou local de estudo, também significa descanso, repouso, lazer, tempo livre; ocupação de um homem com ócio, livre do trabalho servil, que exerce profissão liberal, ou seja, ocupação voluntária de quem, por ser livre, não é obrigado a nada (FARIA, 1962). Estas acepções nos permitem fazer uma associação entre estudo e ludicidade.

De acordo com Cipriano Luckesi, a educação lúdica está fundamentada na concepção de que "o ser humano é um ser em movimento, permanentemente construtivo de si mesmo" e que, "através de sua atividade e consequente compreensão da mesma, constrói-se a cada momento, na perspectiva de tornar-se mais senhor de si mesmo, de forma flexível e saudável" (2000, p. 14). Luckesi destaca ainda que o ser humano modifica a si mesmo enquanto age modificando o mundo, o que acontece de maneira salutar quando feito por meio de atividades lúdicas. (LUCKESI, 2000, p. 17).

Freinet, em A pedagogia do bom senso (2004), afirma que o estudante aprende melhor quando se sente motivado. Segundo Comenius (2001), a motivação para o estudo pode ser alcançada por meio da introdução de um elemento lúdico, que dê leveza ao ensino. Esta leveza pode ser alcançada pela inserção de jogos didáticos ou de outras fatores que tornem as aulas mais agradáveis, como, por exemplo, a utilização de recursos didáticos diferenciados para exposição de conteúdos (quadro de pregas, álbum seriado etc), conforme a tese de Comenius que recomenda a utilização de "figuras, instrumentos de ótica, de geometria, esferas armilares e outros objetos semelhantes que despertam a admiração das crianças e as atraem" (2001, p. 85). Segundo o pai da didática moderna, todos os sentidos devem ser mobilizados para estimular o aprendizado, com particular destaque para a associação entre visão e audição.

A motivação pela ludicidade pode ser particularmente útil no caso das escolas indígenas, quando os alunos têm a necessidade de conviver com conteúdos de uma cultura diferente da sua, com possíveis dificuldades no aprendizado. Alguns problemas foram verificados na Escola Indígena 19 de Abril, onde a alfabetização ocorre primeiro na língua Krahô, sendo esta a única língua utilizada até o quinto ano escolar, continuando como língua de instrução nas séries seguintes, em todas as disciplinas.

Levando em conta que os estudantes Krahô só começam a estudar a língua portuguesa no sexto ano, verifica-se que, ao chegarem ao Ensino Médio, eles têm pouco conhecimento deste idioma, o que acarreta dificuldades para a compreensão de conteúdos mais técnicos. Conforme relato dos professores locais, ocorre a falta de palavras na língua indígena para exprimir determinados conceitos de algumas disciplinas que constam do currículo. Outro 
problema detectado é a dificuldade de interpretação de textos em língua portuguesa. Tendo em vista a necessidade de dominar diversos assuntos e compreender textos mais complexos para poder se conduzir satisfatoriamente na sociedade fora da aldeia, é importante que os estudantes indígenas, sejam conduzidos a um aprendizado mais efetivo no tocante ao trato com a língua portuguesa, de modo a compreender melhor a cultura envolvente e facilitar seu ingresso e permanência no ensino superior. Nesta perspectiva, considera-se que a educação lúdica, como instrumento para ilustrar e esclarecer os conteúdos, pode ser de grande valia para minimizar as lacunas no aprendizado dos estudantes Krahô.

Conforme visto anteriormente, os professores da Escola 19 de Abril já utilizavam a ludicidade, embora restrita a brincadeiras dirigidas às series iniciais, não contemplando os alunos da segunda fase do Ensino Fundamental nem os do Ensino Médio. Convém destacar que a ludicidade é aplicável a todos os níveis de ensino, conforme se percebe na abordagem de Almeida (2013), cujo conceito de educação lúdica parte dos fundamentos sobre o desenvolvimento físico, psicológico, linguístico, cognitivo e ético abordados por pesquisadores contemporâneos, que colocam o lúdico como fator determinante na formação do ser humano e, portanto, essencial ao processo de ensino e aprendizagem. Deste modo, segundo Almeida,

A educação lúdica traz em seu significado um valor de seriedade, inerente ao ser humano em todas as idades, fundamental para o desenvolvimento das múltiplas capacidades e para o processo de construção de conhecimento e, sobretudo, para a formação integral do ser humano, em especial do caráter e da cidadania. (ALMEIDA, 2013, p. 10).

Com base nestes pressupostos, foi elaborada uma proposta de ensino lúdico mediado por recursos visuais alternativos, cujo objetivo era estender o uso da ludicidade a todas as séries, atingindo a todos os estudantes. O público alvo, a princípio, consistia apenas em professores de língua portuguesa, mas como na escola havia apenas um professor desta disciplina, estendeu-se o convite aos demais professores (oito indígenas e dois não-indígenas), que aderiram de bom grado. A proposta baseava-se na oferta de um minicurso composto por oficinas teóricas e práticas, além da aplicação do aprendizado em sala de aula, com posterior comunicação dos resultados obtidos.

No decorrer das oficinas, os professores receberam informações teóricas sobre ludicidade, jogos didáticos e recursos visuais. Na parte prática das oficinas, foram confeccionados diversos materiais visuais que favorecem a instauração de um ambiente mais agradável e interativo para o ensino. Estes materiais incluem diversos tipos de materiais didáticos para ilustração das aulas, tais como flanelógrafo, quadro de pregas e álbum seriado, bem como vários outros específicos para realização de jogos didáticos. Para a segunda fase da pesquisa, os professores deveriam colocar em prática o aprendizado, utilizando os materiais confeccionados em situações concretas de ensino. Posteriormente, por meio de entrevistas, relatariam os resultados da experiência. 


\section{Corrida de Toras: um jogo didático intercultural}

A escolha de um jogo didático para apresentar como componente de um ensino intercultural deve-se ao fato de que os jogos, em suas mais variadas formas, estão presentes em todas as culturas, e têm a propriedade de aproximar pessoas e minimizar diferenças, configurando-se como um valioso recurso didático, porque absorve totalmente os participantes em virtude da existência de dois elementos: o prazer e o esforço espontâneo (HAYDT, 2011). Segundo Haydt, devido ao envolvimento emocional, o jogo é uma atividade com grande capacidade motivacional, capaz de gerar um estado de vibração e euforia. A pesquisadora acrescenta ainda que o jogo mobiliza os esquemas mentais, ativando as funções psiconeurológicas e estimulando o pensamento. Deste modo, "o ser que brinca e joga é também o ser que age, sente, pensa, aprende, se desenvolve. Portanto, o jogo, assim como a atividade artística, é um elo integrador entre os aspectos motores, cognitivos, afetivos e sociais" (HAYDT, 2011, p. 130).

Dentre todos os materiais confeccionados nas oficinas, o jogo Corrida de Toras destacou-se pelo seu caráter de interculturalidade e pela forma como surgiu, pois foi desenvolvido a partir de um outro, apresentado pela pesquisadora, denominado Corrida Maluca, o qual se insere na classificação de jogos de percurso. Este tipo de jogo caracterizase por formar um caminho, dividido em espaços numerados (normalmente chamados de "casas"), o qual deve ser percorrido pelos jogadores tendo em vista alcançar um objetivo que se encontra no final do percurso. Estes jogos normalmente são direcionados para poucos jogadores ( 2 a 4, no máximo) e devem ser jogados sobre uma mesa, motivo pelo qual são também chamados Jogos de Tabuleiro.

O jogo Corrida Maluca (figura 1) é uma adaptação feita para trabalhar simultaneamente com todos os alunos de uma turma, o que tornou necessário um recurso que pudesse ser apresentado na forma vertical para permitir a visibilidade a todos os participantes ao mesmo tempo. Deste modo, o material foi confeccionado em uma superfície de papelão de $50 \times 60 \mathrm{~cm}$, revestida com papel colorido. Para justificar o título do jogo, foram sugeridas figuras de universos diferentes como forma de representar os grupos participantes, tais como um macaco e um elefante ou um carro e um barco. Dependendo da idade dos estudantes e do contexto de ensino, podem ser escolhidos outros símbolos ou objetos relacionados ao tema em estudo. Como se trata de uma corrida, o objetivo do jogo é cruzar a linha de chegada em primeiro lugar, deixando para trás o adversário.

Este jogo atraiu a atenção dos professores indígenas por se tratar de uma corrida entre dois grupos, fazendo-os lembrar das corridas de toras que são praticadas diariamente na aldeia, e que se constituem em um dos elementos mais marcantes da cultura Krahô. 0 momento mostrou-se propício para inserir uma discussão a respeito da possibilidade de mesclar elementos da cultura externa e da cultura Krahô, com base na colocação de Candau: 
A Educação Intercultural parte da afirmação da diferença como riqueza. Promove processos sistemáticos de diálogo entre diversos sujeitos individuais e coletivos -, saberes e práticas na perspectiva da afirmação da justiça - social, econômica, cognitiva e cultural -, assim como da construção de relações igualitárias entre grupos socioculturais e da democratização da sociedade, através de políticas que articulam direitos da igualdade e da diferença. (CANDAU, 2013, p. 01).

Desta forma, assumindo a possibilidade de enriquecimento por meio das diferenças, foi sugerida a criação de um novo jogo que atendesse às preferências dos professores, com o propósito de fazer com que as oficinas fossem uma verdadeira troca intercultural, com crescimento para ambas as partes envolvidas.

Os professores, sentindo-se estimulados, sugeriram a mudança do nome Corrida Maluca para Corrida de Toras, sendo que os grupos seriam representados por desenhos de corredores indígenas, caracterizados como pertencentes às metades mais caraterísticas da cultura, os grupos Wakmẽjê x Katamjê (figura 2). Todos concordaram que, desta forma, fariam um jogo que se aproximava muito mais da sua realidade, o qual, por este motivo, certamente seria muito bem aceito por todos os alunos. Assim, foram desenhados dois corredores indígenas, sendo que a figura que representava o grupo Wakmẽjê foi ornamentada com pinturas horizontais e a do grupo Katamjê, com pinturas verticais, de acordo com a tradição Krahô.

Figura 1 - Jogo original

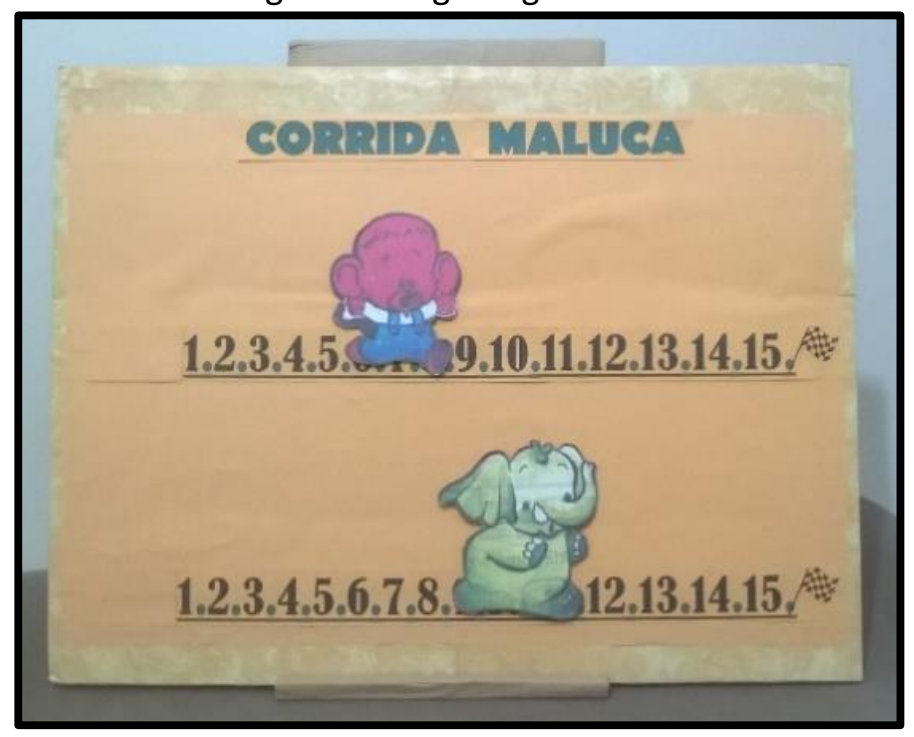


Figura 2 - Jogo produzido pelos professores

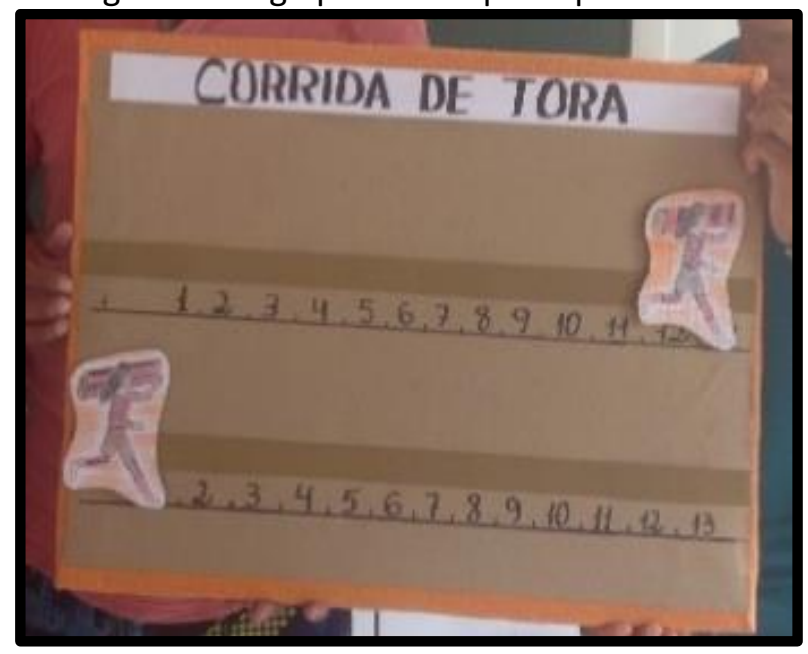

A base foi preparada como no jogo original, com papelão revestido. Para fixação das figuras, foram preparadas duas tiras do mesmo papel utilizado para revestir a base. Estas tiras, medindo $60 \times 5 \mathrm{~cm}$, foram coladas pelas extremidades no sentido horizontal, formando uma espécie de trilho por onde pudessem deslizar as figuras. Em cada um dos trilhos foi feita uma numeração de 1 a 15, sendo os números intercalados por pontos, correspondendo às casas do jogo de percurso. No verso de cada uma das figuras foi colado um pedaço de papel cartão $(5 \times 2 \mathrm{~cm})$, no sentido vertical, deixando a parte de baixo livre para encaixar no trilho.

Após o preparo do material, os professores foram orientados quanto ao funcionamento do jogo, tanto no que se refere ao deslizamento dos corredores pelos trilhos, como em relação às regras, para que se lembrassem de explicá-las previamente a seus alunos a fim de evitar contratempos. Não houve dificuldades por parte dos professores, seja na confecção do material, seja no entendimento das regras, descritas a seguir. Com relação à definição dos grupos, no jogo Corrida Maluca, costuma-se utilizar estratégias variadas, como, por exemplo, distribuição de números, separando-se os pares e ímpares. No caso do Corrida de Toras, os professores esclareceram que não haveria necessidade de estratégia para divisão, uma vez que todos os alunos já estão incluídos em um dos grupos Wakmẽjê e Katamjê. Desta forma, sempre que fossem realizar o jogo na classe, a divisão dos grupos ocorreria de forma automática.

Nos jogos de percurso tradicionais, o avanço dos jogadores é feito com base nos números estabelecidos em jogadas com dados. Neste caso, por se tratar de um jogo didático, cada grupo avança uma casa após ter respondido corretamente uma pergunta feita pelo professor. Caso a pergunta não seja respondida a contento, o grupo permanece na mesma casa. A pergunta deve ser passada para o grupo seguinte, que avançará caso acerte a resposta. Em seguida, o mesmo grupo responderá outra pergunta, que lhe cabe pela sequência do jogo, o qual será vencido pelo grupo que chegar primeiro à casa de número 15. 
Para cada sessão de jogos, o professor deve preparar, de antemão, 30 perguntas, de acordo com o conteúdo que estiver sendo estudado. Percebe-se, portanto, que é um jogo versátil, que pode ser utilizado em qualquer disciplina, com qualquer tipo de conteúdo.

Após a realização das oficinas, os professores tiveram um período de tempo para aplicarem os materiais em suas aulas, sendo orientados a anotar os resultados e as reações dos alunos. Depois deste tempo, houve uma reunião entre professores e pesquisadora para avaliação dos resultados do trabalho com os novos materiais. Neste encontro foi realizada uma entrevista com os professores para identificar quais foram os materiais utilizados e se os objetivos foram alcançados. Os professores relataram como foram suas aulas com as novas dinâmicas, falando como utilizaram os materiais e qual a reação dos alunos. Em relação ao jogo Corrida de Toras, os professores ${ }^{5}$ comentaram que utilizaram em diversas disciplinas e séries variadas, inclusive no Ensino Médio.

No tema ... a gente pesquisa da cultura ... então brinquei com eles os nomes das frutas ... assim ... dividi os partidos Catàmjê e Wacmẽjê, ((corrida de toras)), fiz tipo um ditado ... se o Wacmẽjê acertava o nome que eu falei, a torinha deles andava ... no 60 ano, dentro da disciplina cultura e diversidade, brinquei também ... era também um ditado, com o nome das festas, eu falava o nome da festa, se eles conseguiam escrever no quadro direitinho, a torinha do partido deles andava. (Prof. E).

[...] Trabalhei também com eles a corrida de tora. Perguntava algumas coisas, e o partido que acertava, ia pra frente. Perguntei, de matemática ... 3×3, 4×5 ... O partido respondia, o corredor andava. (Prof. H).

... usei também a corrida de toras. Então eu pegava uma pergunta ... os alunos que estavam presentes ... por que tem dois partidos, Wacmẽjê e Catàmjê, verão e inverno ... se o partido do verão respondia a pergunta, da história que ele contou, se acertava, então o corredor do partido deles andava. Foi assim que eu trabalhei ((Ensino Médio)). (Prof. J).

No tocante às dificuldades dos alunos e o papel do jogo em minimizá-las, todos os relatos foram muito positivos. Dois professores comentaram que os alunos, de modo geral, eram bastante tímidos, mas o recurso visual foi um incentivo para que eles perdessem a vergonha e começassem a participar mais, seja com perguntas, no decorrer da aula, ou com interesse em dar respostas corretas no momento dos jogos.

Assim ... a gente escreve o nome ... por exemplo, das frutas. Para falar, eles aprendem mais rápido ...mas na leitura ... eles tem dificuldade de relacionar o que está escrito com o que foi falado ... e eles precisam então treinar mais. $\mathrm{E}$ eles gostaram, também, da brincadeira ... então ... ((o material)) ajudou sim, porque antes, na hora das perguntas, eles ficavam com medo, mas agora, com

\footnotetext{
${ }^{5}$ Tendo em vista a preservação da identidade dos docentes, foram utilizadas letras em lugar dos nomes.
} 
a corrida, eles já ficam mais animados, porque pensam: se eu acertar, a torinha vai andar, já vai chegar primeiro no final. (Prof. E).

Sim ... no primeiro dia, ... eles ... como eles são tímidos, eles têm, assim, vergonha ... mas aos poucos foram se adaptando. Agora, eles gostam, porque também é uma aula dinâmica e eles aprendem. [...] Eles participam, participam agora ... Perderam a vergonha ... agora, eles participam bastante. Foi muito bom para eles. (Prof. I).

Ajudou ... eles gostaram ... perguntaram é só isso que pode brincar? Não, eu falei, pode brincar também na matemática ... outras coisas também ... eu falei assim pra eles, e eles gostaram ... quero usar de novo ... eu usei também aquele da torinha ... eu perguntava algumas coisas ... perguntei assim $3 \times 3,4 \times 5$ ... e cada partido, quando acertava, a torinha andava... com isso, eles animaram, foi bom. (Prof. $\mathbf{H}$ ).

Todas as respostas apontaram para a interação que a atividade promoveu entre os alunos, confirmando a versatilidade do jogo, e o quanto um elemento vindo da cultura externa pode ser transformado de forma a se tornar algo útil para o fortalecimento da cultura indígena. A experiência demonstrou que o encontro entre culturas pode ser produtivo, confirmando a afirmação de Geertz (1989) de que nas relações entre culturas diferentes pode ser desenvolvido o conhecimento do ser humano, tornando-se mais compreensíveis os sentidos que as ações de cada um assumem nos seus respectivos contextos culturais. Fleuri corrobora esta posição, demonstrando a importância, no processo educativo, da relação entre culturas de uma forma igualitária:

Recuperar o papel das culturas no processo educacional, tanto em nível pessoal como coletivo, implica reconhecer a interação entre diferentes modos de ser humano, que se desenvolvem como forças em tensão. Tais campos de força, intensamente conflitantes, podem estabelecer formas criativas de interação entre culturas diversas, possibilitando a reinvenção da existência humana. (FLEURI, 2003, p. 70).

Confirmando a colocação de Fleuri, a criação e utilização do jogo Corrida de Toras foi uma espécie de reinvenção de relações culturais, mesclando elementos da cultura envolvente com outros da cultura indígena, com saldo positivo para todos os envolvidos, levando à conclusão de que os conflitos oriundos da relação entre culturas podem ser tratados de maneira criativa e enriquecedora, valorizando os relacionamentos humanos e as particularidades de cada cultura.

\section{Considerações finais}

Partindo do pressuposto de a ludicidade tem o potencial para promover aprendizagens significativas e duradouras, foi elaborada uma proposta de intervenção para a Escola Indígena 
19 de Abril, tendo como objetivo capacitar os professores desta escola para a utilização de recursos visuais alternativos. Foram realizadas oficinas nas quais os professores aprenderam sobre recursos visuais e educação lúdica, tanto na teoria como na prática.

Este artigo concentrou-se na descrição de uma parte da pesquisa, a criação do jogo didático Corrida de Toras, caracterizado como integrador, por entrelaçar elementos das duas culturas envolvidas. Houve intensa participação dos professores, que perceberam a validade de utilizar a interculturalidade em um jogo didático a fim de otimizar sua prática docente.

Após a conclusão da fase de aplicação dos materiais confeccionados nas oficinas, os professores mostraram-se animados com os resultados e interessados em continuar a utilizar os novos recursos de maneira mais consistente em suas aulas. Os relatos apontaram para um resultado extremamente positivo no uso do jogo Corrida de Toras, o que contribuiu para que fosse possível atender à recomendação do Referencial Curricular Nacional para as Escolas Indígenas no sentido de promover o entendimento e o respeito entre culturas diferentes, mesclando experiências socioculturais e linguísticas diferentes sem considerar uma cultura superior à outra (BRASIL, 1998, p. 24), fatos que caracterizam um ensino verdadeiramente intercultural.

\section{Referências}

ABREU, Marta Virginia de Araújo Batista. Situação sociolinguística dos Krahô de Manoel Alves e Pedra Branca: uma contribuição para educação escolar. Dissertação de mestrado. Araguaína: Universidade Federal do Tocantins - UFT, 2012.

ALBUQUERQUE, Francisco Edviges. Índios do Tocantins: aspectos históricos e culturais. In: SILVA, Norma Lúcia da; VIEIRA, Martha Victor. Ensino de história e formação continuada: teorias, metodologias e práticas. Goiânia: Ed. PUC Goiás, 2013. p. 135-158.

ALBUQUERQUE, Francisco Edviges. (Org.) Português Krahô. Campinas: Pontes Editores, 2014. ALMEIDA, Paulo Nunes de. Educação lúdica: teorias e práticas. Vol. 1 Reflexões e fundamentos. São Paulo: Edições Loyola, 2013.

ARAÚJO, Marcilene de Assis Alves. Eventos de interação nos rituais Krahô (jê): contribuições para o ensino bilíngue na aldeia Manoel Alves Pequeno. Tese de doutorado. Universidade Federal do Tocantins - UFT, 2015.

BRASIL. Decreto Presidencial no 102, de 05 de agosto de 1944. Define a extensão da Terra Kraolândia. Diário Oficial do Estado de Goiás de 10 de agosto de 1944, ano I, no 150, p. 1. Disponível em: http://www.jusbrasil.com.br/diarios/2447529/pg-24-secao-1-diario-oficialda-uniaodou -de-05-08-1944. Acesso em: 13 dez. 2016.

BRASIL. Lei Ordinária no 6001, de 19 de dezembro de 1973. Cria o Estatuto do Índio, Brasília, DF: 1973.

BRASIL. Constituição da República Federativa do Brasil. Brasília, DF: Senado Federal: Centro Gráfico, 1988. 
BRASIL. Decreto Presidencial no 99.062, de 07 de março de 1990. Homologa a demarcação da Área Indígena Kraolândia. Diário Oficial do Estado do Tocantins, 07 de março de 1990. Disponível em: ttp://legis.senado.gov.br/legislacao/ListaTextolntegr I.action?id=111095\&norma=133746. Acesso em: 13 dez. 2016.

BRASIL. Diretrizes para a Política Nacional de Educação Escolar Indígena. 2. ed. Brasília: MEC/ SEF/DPEF, 1994.

BRASIL. Lei de Diretrizes e Bases da Educação Nacional. Lei no 9.394, de 20 de dezembro de 1996.

BRASIL. Referencial Curricular Nacional para as Escolas Indígenas. Brasília: MEC/SEF, 1998.

BRASIL. Lei federal 10.172. Plano Nacional de Educação. Brasília: MEC, 2001.

CANDAU, Vera Maria. Educação Intercultural. GECEC- PUC-Rio. (documento de trabalho), 2013.

COMENIUS, Iohannis Amos. Didactica Magna. Lisboa: Calouste Gulbenkian, 2001.

FARIA, Ernesto (Org.). Dicionário escolar latino-português. 3. ed. Rio de Janeiro: MEC Ministério da educação e cultura. Departamento Nacional de Educação, 1962.

FLEURI, Reinaldo Mathias. Desafios à educação Intercultural no Brasil. In: FLEURI, Reinaldo Mathias (Org.). Intercultura: Estudos emergentes. Ijuí (SC), EdUnijuí, 2001, p. 129-150.

FREINET, Célestin. Pedagogia do bom senso. 7. ed. São Paulo: Martins Fontes, 2004.

GEERTZ, Clifford. A interpretação das culturas. Rio de Janeiro: Guanabara Koogan, 1989.

GUIMARÃES, Susana Martelletti Grillo. Diretrizes da educação escolar indígena. In: PARANÁ, Secretaria de Estado da Educação. Coordenação da Educação Escolar Indígena. Educação Escolar Indígena. Curitiba: SEED/PR, 2006. (Cadernos Temáticos). p. 18-22.

HAYDT, Regina Célia Cazaux. Curso de didática geral. São Paulo: Ática, 2011.

LEITE, Francinaldo Freitas. Saberes tradicionais Krahô: contribuições para a educação física indígena bilíngue e intercultural. Dissertação de mestrado. Araguaína, TO: Universidade Federal do Tocantins, 2017.

LUCKESI, Cipriano Carlos. Educação, ludicidade e prevenção de neuroses futuras: uma proposta pedagógica a partir da Biossíntese. In: LUCKESI, Cipriano Carlos (Org). Educação e Ludicidade, Ensaios 01. Salvador: GEPEL, Universidade Federal da Bahia, 2000.

MACEDO, Aurinete Silva. Saberes tradicionais Krahô e educação escolar indígena: um diálogo possível na Escola Indígena 19 de Abril. Dissertação de Mestrado. Araguaína: UFT, 2015.

MAHER, Terezinha Machado. Do casulo ao movimento: a suspensão das certezas na educação bilíngue e intercultural. In: CAVALCANTI, Marilda C.; BORTONI-RICARDO, Stella Maris. Transculturalidade, linguagem e educação. Campinas, SP: Mercado de Letras, 2007. p. 67-94.

MAHER, Terezinha Machado. Formação de Professores Indígenas: uma discussão introdutória. In: GRUPIONI, Luís Donisete Benzi (Org.). Formação de professores indígenas: repensando trajetórias. Brasília: MEC/SECADI, 2006. p. 11-38. 
MELATTI, Julio César. Índios e criadores: A situação dos Krahô na área pastoril do Tocantins. Edição do autor, em pdf. Brasília, 2009. Disponível em <http: //www. Julio melatti.pro.br/livros/livro67.pdf>. Acesso em 08 set. 2016.

MELATTI, Julio César. Corrida de Toras. Revista de Atualidade Indígena, Brasília, ano I, n. 1, p. 38-45, 1976. Disponível em <http://www.juliomela tti.pro.br/artigos/a-toras.pdf>. Acesso em 05 out. 2016.

MELATTI, Julio César. O Sistema Social Craô. Tese de doutorado (1970). Edição do autor, em pdf. Brasília, 2012. Disponível em <http://www.juliomelattipro.br/tese/teseindice.pdf>. Acesso em 22 nov. 2015.

MELIÀ, Bartomeu. Educação Indígena e Alfabetização. São Paulo. Ed.: Loyola. 1979.

MORI, Angel Corbera. A língua indígena na escola indígena: quando, para que e como? In: VEIGA, Juracilda; SALANOVA, Andrés (orgs). Questões de educação escolar indígena: da formação do professor ao projeto de escola. Brasília: FUNAI/DEDOC, Campinas/ALB: 2001. p. 160-171.

NIMUENDAJÚ, Curt. A habitação dos Timbira. Revista do Patrimônio histórico e artístico nacional. Rio de Janeiro, 1944. Biblioteca Digital Curt Nimuendaju. Disponível em <http:// www.etnolinguistica.org>. Acesso em: 16 set. 2016.

NIMUENDAJÚ, Curt. The Eastern Timbira, University of California Publications in American Archaeology and Ethnology, v. 41, University of California Press, Berkeley and Los Angeles, 1946.

PLATÃO. A república. Trad. Enrico Corvisieri. São Paulo: Nova Cultural, 2000.

RIBEIRO, Francisco de Paula. Memoria sobre as nações gentias que presentemente habitam o Continente do Maranhão: analyse de algumas tribus mais conhecidas: processo de suas hostilidades sobre os habitantes: causas que lhes tem difficultado a reducção, e unico methodo que seriamente poderá reduzil-as. Revista Trimensal de Historia e Geographia ou Jornal do Instituto Historico e Geographico Brasileiro. Rio de Janeiro: tomo 3ํ, n. 10, p. 184197, 1841.

TOCANTINS. Proposta Pedagógica da Educação Escolar Indígena. Palmas: SEDUC/TO, 2013.

Recebido em: 24/09/2018

Aceito em: 31/01/2019 